\title{
Traction network currents distribution under different power supply voltage
}

\author{
Sopov Valentin Ivanovich \\ Department of electrotechnological units \\ Novosibirsk state technical university \\ Novosibirsk, Russian Federation \\ sopov@corp.nstu.ru
}

Abramov Evgeniy Yrievich

Department of electrotechnological units

Novosibirsk state technical university

Novosibirsk, Russian Federation

e.abramov@corp.nstu.ru

\author{
Schurov Nikolay Ivanovich \\ Department of electrotechnological units \\ Novosibirsk state technical university \\ Novosibirsk, Russian Federation \\ shhurov@corp.nstu.ru \\ Langeman Evelina Garrievna \\ Department of electrotechnological units \\ Novosibirsk state technical university \\ Novosibirsk, Russian Federation \\ langeman@corp.nstu.ru
}

\begin{abstract}
Factors that generate power supply voltage and current distribution in traction networks are considered. Determination methods of the current distribution in the substation area for double power supply sections of a traction network for transport route are provided. A calculation method of currents in traction network elements based on equivalent electromotive forces and currents, which allows solving the task of choosing section schemes of traction network and determination of the electrical quantities with a high accuracy, is shown.
\end{abstract}

Keywords-electrical transport, electric stock, traction substation, power supply, catenary, recuperation, current distribution, electric power supply.

\section{INTRODUCTION}

Satisfying modern requirements for the power supply system of urban and mainline electric transport comes in two main directions. The first is to maximize an improvement of system elements. However, the second direction development of progressive systems of traction power networks in general is much more important for technoeconomic effect.

The analysis of ensuring energy efficiency and reliability of power supply systems of electrical transport showed that a necessary condition for the implementation of its main objectives is the development of a number of theoretical and experimental questions. That primarily involves the development of electric and economic calculations of power supply devices, as well as a study of circuits and devices of traction networks.

Traction substations (TSS) and network operate in conditions that are significantly different from the stationary work conditions of electric power plants. These differences are determined primarily by loads features of traction networks that are formed by overlapping currents, consumed by the traction motors, and electric needs of its own composition. One of the most important features of traction networks is the difference of the power supply output voltages that are connected to contact network. In this regard, designing the traction networks involves the task of determining of currents distributions and power sections of the contact network. Knowledge of electric loads in power supplies and conductive networks is necessary for the choice of their parameters (power, sections), as well as technical and economic calculations. Calculation of currents distribution is a more difficult task due to the use of the recovery mode, the transfer of energy of electric braking through the catenary and application of energy storage devices for improving the system energy efficiency.

Thus, two types of energies appeared in the electric traction system: external - from the energy systems, and internal - owing to electrical braking. The overlay of these two energies brought a change in currents modes and traction network voltages. The processes of their changing are becoming more stochastic.

Electric power supply devices calculations are one of the main means for the correct choice of appropriate system parameters. In addition, they serve for checking the conformity of selected parameters to all electrical requirements and conditions of the actual implementation of a specified amount of traffic.

The significance of a well-established methodology for electrical calculations is obvious. Lately, a number of works on solving the problem of braking energy use and optimization of the currents distribution in traction networks have appeared [1-4]. Questions of currents distribution had previously been dealt with in a number of monographs $[5,6]$ and educational literature. A common disadvantage of these works is an investigation of the operation modes of only one substation area. The objective of the present research is to develop a common methodology for evaluating currents distribution in transport lines. 


\section{TRACTION NETWORK SCHEMES AND THEIR INFLUENCE ON CURRENTS DISTRIBUTION}

The schemes of catenary sections power supply affect the currents distribution significantly. The following power schemes and sections in substation area of double line are used [7, 8]:

- separate or parallel single power supply (fig. 1,a);

- separate and parallel double power supply (fig. 1,b);

- node with section pillars and parallel connection posts (fig. 1,c).

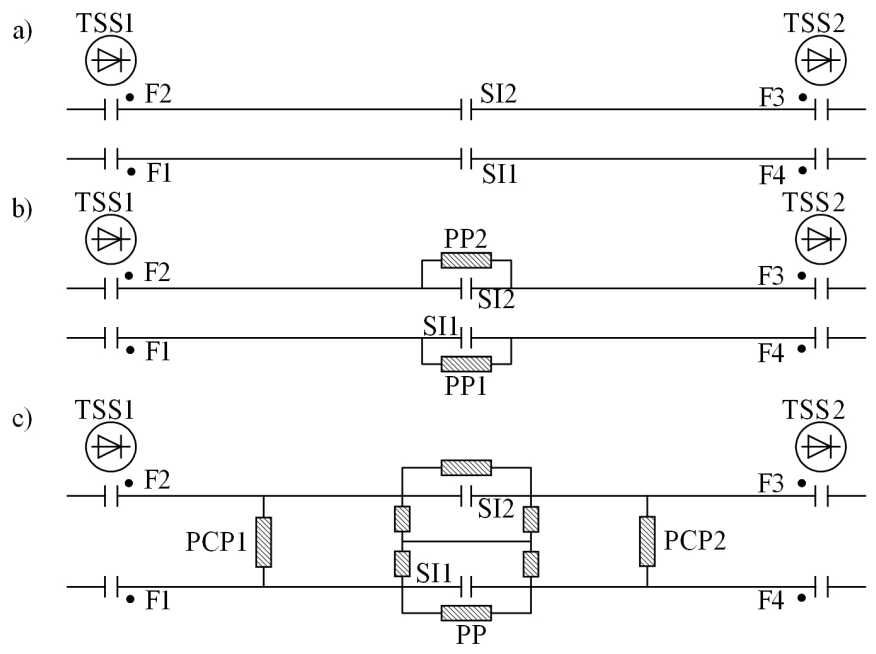

Fig.1. Schemes of power supply and catenary sections

Sections are connected with one traction substation feeder in schemes of single power supply. The general scheme of currents is shown in Fig. 2.

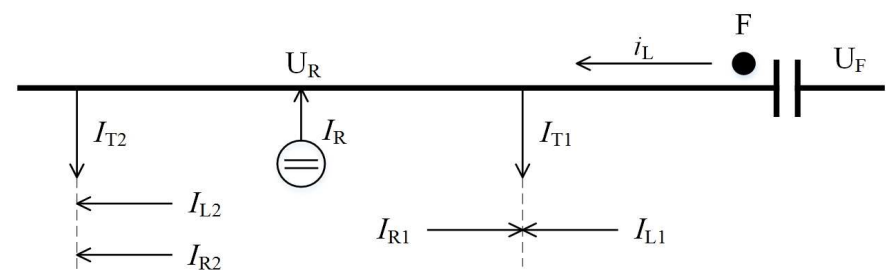

Fig. 2. Scheme of currents: $I_{\mathrm{T} 1}, I_{\mathrm{T} 2}-$ traction; $I_{\mathrm{R}}=I_{\mathrm{R} 1}+I_{\mathrm{R} 2}-$ recuperation; $i_{\mathrm{L}}, I_{\mathrm{L} 1}$, $I_{\mathrm{L} 2}-$ lines

The task comes down to assessing network currents, taking in to account the following factors:

- the difference of recuperation voltage of substation feeder $U_{\mathrm{R}} \geq 1.2 \cdot U_{\mathrm{F}}$

- restriction of the recuperation currents $-I_{\mathrm{R}} \leq I_{\mathrm{T} 1}+I_{\mathrm{T} 2}+I_{\mathrm{Tn}}$, where $n$ is the number of traction currents;

- current $I_{\mathrm{R}}$ decrease as slowing down before stopping or dangerous slopes.

The total energy of electric braking is determined by the formula [2]:

$$
\begin{aligned}
M A X W_{\mathrm{R}} & =\left(0.01073(1+\gamma) \cdot G\left(V_{\mathrm{ST}}^{2}-V_{\mathrm{FIN}}^{2}\right)-\right. \\
& \left.-2.725 \cdot G\left(w_{0} \pm i_{\mathrm{e}}\right) \cdot S\right) \cdot h_{\mathrm{R}} .
\end{aligned}
$$

In equation (1): $G$ - train weight; $1+\gamma-$ a coefficient of rotating parts inertia; $V_{\mathrm{ST}}, V_{\mathrm{FIN}}$ - start and final braking speed; $w_{0}$ - specific primary resistance movement; $S$ - breaking length.

During the recuperation breaking, only this energy is used and could be defined with the use factor:

$$
K_{\mathrm{U}} \cdot W_{\mathrm{R}}=K_{\mathrm{U}} M A X W_{\mathrm{R}}
$$

Thus, recuperative currents only implement the main currents from substations. In general terms, identification of the proportion of these currents analytically is difficult.

Sections with double power supply have a number of advantages in comparison with the single power supply scheme: up to $20-25 \%$ of reduced power loss; sections power redundancy of catenary (increased supply reliability) is provided; reduced power of traction substations converter units; increased substation area and probability of effective regenerative breaking energy use when it passes through the catenary. Thus, it creates more favorable input modes voltage, conditions of automation are improved and operating costs due to the reduction of energy losses are reduced.

Anchor circuits are formed using partitioning posts (PP) and parallel connection posts (PCP). Here are useful posts of the transistor circuit, which switches are shown in Figure 3.

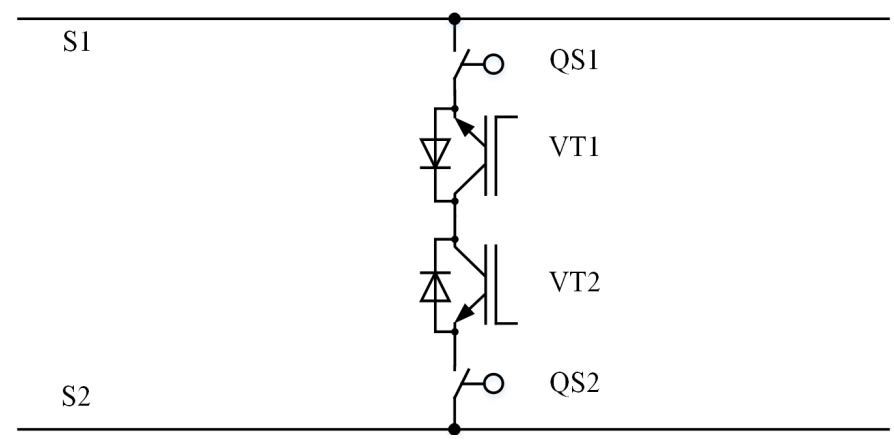

Fig. 3. Scheme of parallel connection post with transistor switch

Nodes in catenary have a significant effect on the currents distribution.

Electric traction systems feature with double power supply sections is to combine the catenary with the multiple power sources circuit. A number of problems appear when sections with double power supply are connected sequential. The system becomes sensitive to power supply voltages, uncertainty of currents distribution in catenary appears. When the different parallel power supplies voltages, so-called cross currents appear. That can significantly degrade the performance indicators of electricity due to the growth of energy losses, negative impact on the functioning of electric stock, complications of protection relays work, catenary overheating, accelerated insulation deprecation, etc. Depending on the parameters of the power section, the value of power losses from the cross current in the double power supply scheme will be different. With a high asymmetry of 
currents distribution, it may exceed the amount of total losses of single power supply schemes.

This kind of schemes is used on electric railways, subways, trams and trolleybuses.

In research [5], it is shown that for traction substations of urban electric transport during the parallel work of traction substations, the difference of voltage on the DC bus is consistently 10-40 V, and the greatest variation reaches $60-80$ $\mathrm{V}$. The recommendation is to use the double power supply for the section only when the difference in voltages does not exceed $15 \mathrm{~V}$.

\section{REASONS OF DIFFERENT POWER SUPPLY VOLTAGES}

Voltages levels are formed under the influence of a number of factors, such as continuous load fluctuations, the difference in number of included converting units for traction substations, their external characteristics, and resistance of feed lines. In addition, traction substations of a subway, a tram, a trolleybus and a part of electric railway receive electricity from the isolated centers with different output voltage. For example, in Figure 4 records show stresses on 10 $\mathrm{kV}$ neighboring substations inputs connected to one section.

Records were obtained using the energy recorder PKE-1. Measured data show that the difference of voltage is 300-350 $\mathrm{V}$. In terms of $825 \mathrm{~V}$ DC voltage, the difference is $25-28 \mathrm{~V}$.

The second factor is the difference of external characteristics due to internal resistance [6]:

$$
\rho=U_{\mathrm{d} 0} / I_{\mathrm{dn}} \cdot\left[A \cdot\left(U_{\mathrm{sc}} \% / 100 \cdot N+S_{\mathrm{n}} / S_{\mathrm{sc}}\right)+\Delta P_{0} \% / 100\right]+R_{0}+R_{1} .
$$

In equation ( 3$): A \approx 0.5$ - factor of external characteristics obliquity; $S_{\mathrm{n}}, S_{\mathrm{sc}}-$ power of the nominal and short current operation mode on $10 \mathrm{kV}$ bus composite traction step-down substations; $\Delta P_{0} \%$ - power losses in the transformer windings; $U_{\mathrm{d} 0}, I_{\mathrm{dn}}$ - open circuit voltage and the nominal current of the converter; $R_{1}$ is the resistance of the power supply line converted to DC-side; $R_{0}$ is the resistance of the cables from the traction substations buses.

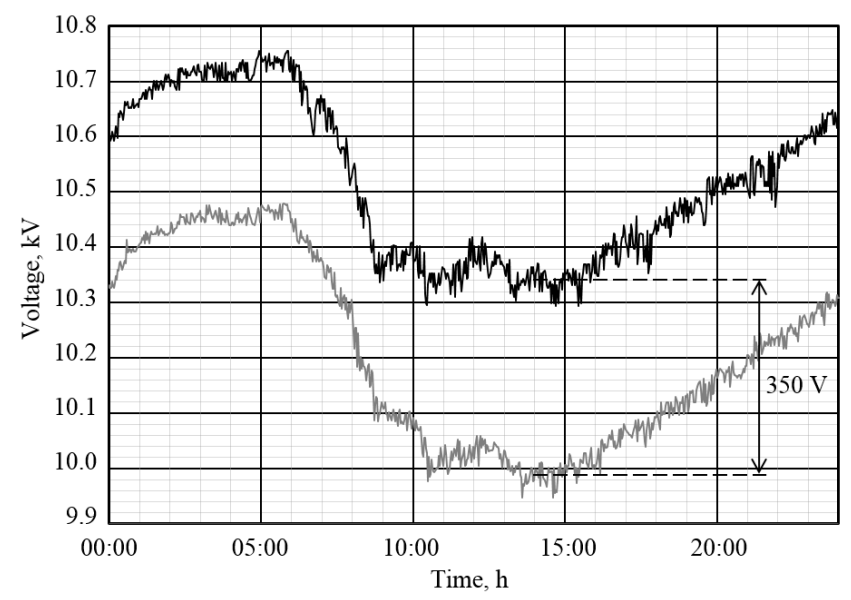

Fig. 4. Voltage on inputs $10 \mathrm{kV}$ neighboring subway substations
As one can see from (3), neighboring traction substations parameters are usually different, and $\rho$ is not equal.

The output voltage on the connecting pantograph in the recuperation mode takes $20 \%$ above nominal in the network $[9,10]$. Traction and recuperative currents cause voltage losses in the feed lines, contact network, and aggregates of traction substations. Thus, the task of determining the voltage levels on the power supply and pantographs is complicated and goes into the field of stochastic processes.

\section{ANALYTICAL SCHEME OF TRANSPORT NETWORK SECTION}

The analytical scheme for the double power supply section is shown in figure 5 .

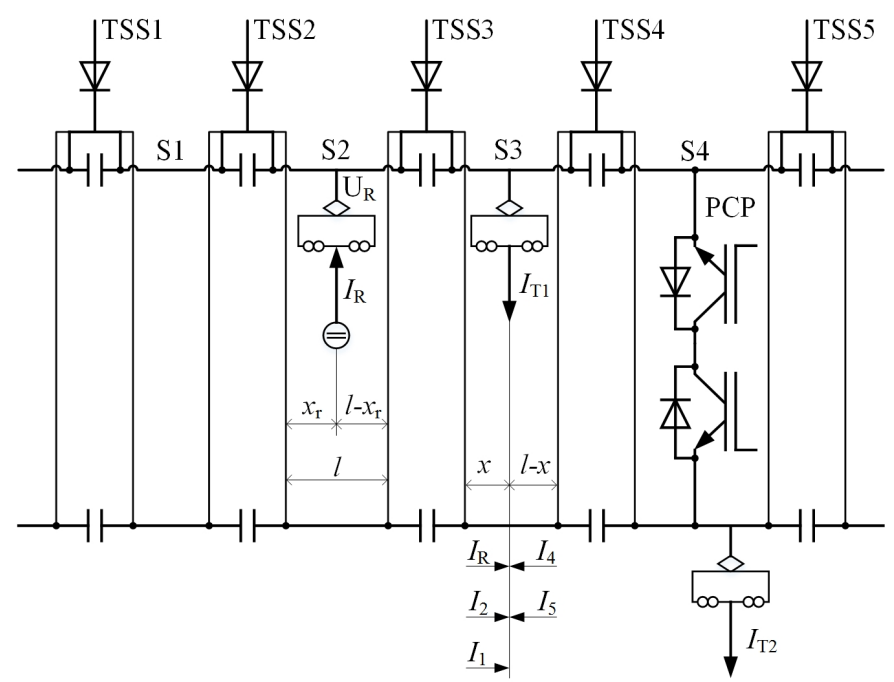

Fig.5. Scheme of transport network with double power supply sections

The scheme in figure 5 is for separate supply sections. However, applying the parallel connection posts and sectioning posts, one can pass on the node schemes and schemes with full sections connection of parallel paths.

The calculation allows finding the percentage of power supply currents in traction current $\left(I_{\mathrm{T} 1}, I_{\mathrm{T} 2}\right)$. The scheme shows the currents of power supply, including recuperation ones. There are following assumptions for currents distribution assessment: the current of the train is constant, equal to the average value. Trains' movement is equable. One train is on one section; the length of the sections is the same and equal to $l$, trains' position coordinates are $x$ and $x_{\mathrm{r}}$; traction network parameter $-r, \mathrm{Ohm} / \mathrm{km}$.

\section{CALCULATION OF CURRENTS DISTRIBUTION IN SUBSTATION AREA}

Let us consider the currents distribution in the first path that corresponds to the sections with full parallel connection. The scheme is shown in Fig. 6.

Let us consider the current distribution in section S3 in the substation area of TSS3-TSS4. In the case of equipotential mode $U_{3}=U_{4}, i_{\mathrm{L} 1}$ and $i_{\mathrm{L} 2}$ currents distributed back-in proportion to the distances when $\mu=$ const. 


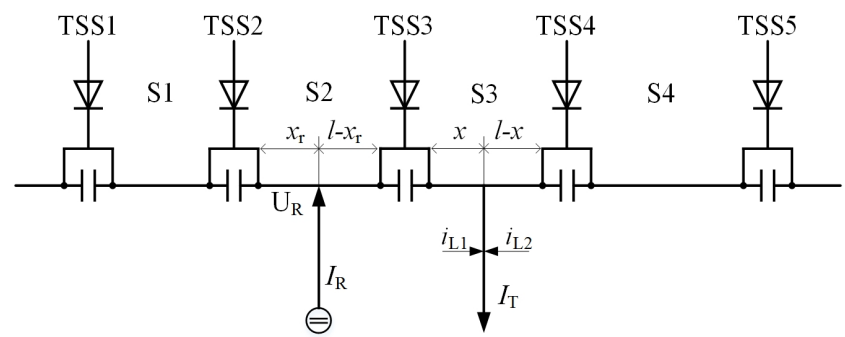

Fig.6. Calculation scheme of traction network section

$$
\begin{gathered}
i_{\mathrm{L} 1}=I_{\mathrm{T}^{*}} \cdot(l-x) / l ; \\
i_{\mathrm{L} 2}=I_{\mathrm{T}} \cdot x / l .
\end{gathered}
$$

When $n$-traction currents are on the section, then line currents are defined by the formulas:

$$
\begin{gathered}
I_{\mathrm{L} 1}=1 / l \Sigma I_{\mathrm{T}} \cdot x ; \\
I_{\mathrm{L} 2}=1 / l \Sigma I_{\mathrm{T}} \cdot(l-x) .
\end{gathered}
$$

For further analysis, let us move to a system of relative units. Let us denote:

$$
\begin{gathered}
x / l=x_{*} ; \\
1 / l=1 ; \\
i_{\mathrm{L} 1} / I_{\mathrm{T}}=i_{* 1} ; \\
i_{\mathrm{L} 2} / I_{\mathrm{T}}=i_{* 2} ; \\
U_{3}-U_{4} / r \cdot I_{\mathrm{T}} \cdot l=i_{* \text { cross }} .
\end{gathered}
$$

If $U_{3}=U_{4}-$ there is an equipotential mode of current distribution in relative units, obtained through the following expression:

$$
\begin{gathered}
i_{* 1}=1-x_{*} ; \\
i_{* 2}=x_{*} .
\end{gathered}
$$

The nomograph is shown in Fig.7.

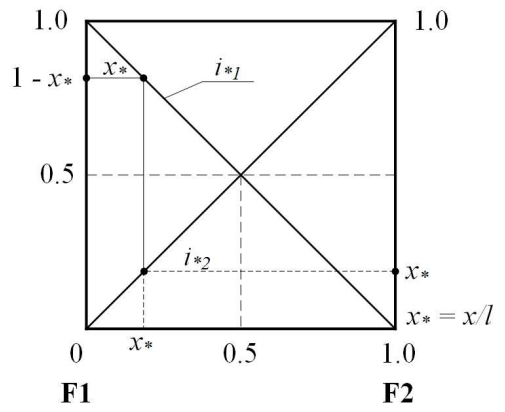

Fig. 7. Current distribution nomograph for equipotential mode
The nomograph is useful in calculation of instantaneous schemes. Upon the location of the trains on the section, the proportion of train currents relegated to the feeder (TSS3TSS4) could be quickly found.

In the case of the nonequipotential mode $U_{3} \neq U_{4}$ : for power supply, pantograph voltage can be defined as:

$$
U_{\mathrm{T}}{ }^{\prime}=U_{3}-i_{\mathrm{L} 1} \cdot r x
$$

$$
U_{\mathrm{T}}{ }^{\prime \prime}=U_{4}-i_{\mathrm{L} 2} \cdot r(l-x)
$$

$$
i_{\mathrm{L} 1}+i_{\mathrm{L} 2}=I_{\mathrm{T}}
$$

Taking into account that $U_{\mathrm{T}}{ }^{\prime}=U_{\mathrm{T}}{ }^{\prime}$, , let us obtain the equation in the following form if $U_{3}>U_{4}$ :

$$
\begin{array}{r}
i_{\mathrm{L} 1}=I_{\mathrm{T}} \cdot(l-x) / l+\left(U_{3}-U_{4}\right) / r l \\
i_{\mathrm{L} 2}=I_{\mathrm{T}} \cdot x / l-\left(U_{3}-U_{4}\right) / r l .
\end{array}
$$

In dimensionless units, equations $(13,14)$ will get a view:

$$
\begin{gathered}
i_{* 1}=1-x_{*}+V_{*_{\mathrm{c}}} ; \\
i_{*_{2}}=x_{*}-V_{*_{\mathrm{c}}} .
\end{gathered}
$$

The summand of current $V_{*_{\mathrm{c}}}$ can be called a voltage coupling coefficient.

The currents distribution nomograph for the case of nonequipotential is shown in fig. 8 .
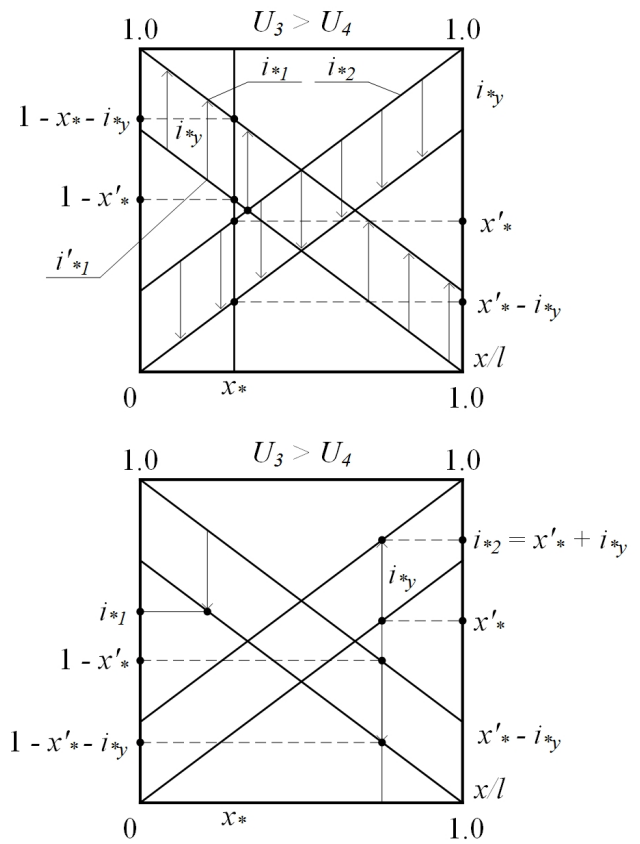

Fig.8. Currents distribution for different sources voltage

An example. Let us consider a methodology for evaluating currents distribution, for example, of the underground traction 
network. The section schemes with two traction currents are shown in Fig. 9.

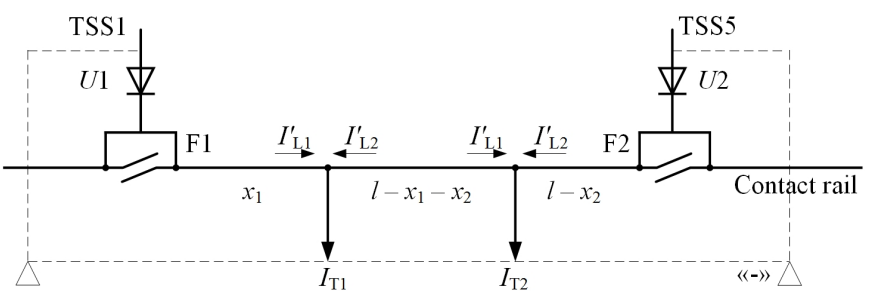

Fig. 9. Scheme for example calculation

The following source data were taken for this example:

$l=1.5 \mathrm{~km}-$ relegated section length;

$r=25 \cdot 10^{-3} \mathrm{Ohm} / \mathrm{km}-$ traction network parameter;

$x_{1}=0.5 \mathrm{~km}, x_{2}=1.0 \mathrm{~km}$;

$I_{\mathrm{T} 1}=700 \mathrm{~A}, \mathrm{I}_{\mathrm{T} 2}=500 \mathrm{~A}$;

$\Delta U=U_{1}-U_{2}=20 \mathrm{~V}$.

Equipotential mode is $U_{1}=U_{2}$. The relative value of coordinates is $I_{\mathrm{T} 1}$, the share of current is $\mathrm{F} 1$, current $I_{\mathrm{L}}$ ' and current flowing from $\mathrm{F} 2$ to $i_{* 2}{ }^{\prime}=x_{*}$, respectively:

$$
\begin{gathered}
x_{*}=500 / 1500=0.33 ; \\
i_{* 1}{ }^{\prime}=1-x_{*}=1-0.33=0.67 ; \\
I_{\mathrm{L}}{ }^{\prime}=0.67 \cdot 700=469 \mathrm{~A} ; \\
I_{\mathrm{L} 2}{ }^{\prime}=0.33 \cdot 700=231 \mathrm{~A} .
\end{gathered}
$$

By analogy, let us define the current line for $I_{\mathrm{T} 2}$ :

$$
\begin{gathered}
x_{*}=1000 / 1500=0.67 ; \\
I_{\mathrm{L} 1}{ }^{\prime}=(1-0.67) \cdot 500=165 \mathrm{~A} ; \\
I_{\mathrm{L} 2}{ }^{\prime}=0.67 \cdot 500=335 \mathrm{~A} .
\end{gathered}
$$

Feeders currents are:

$$
\begin{aligned}
& I_{\mathrm{L} 1}=469+165=634 \mathrm{~A} ; \\
& I_{\mathrm{L} 2}=231+335=566 \mathrm{~A} .
\end{aligned}
$$

Nonequipotential mode is $U_{1}>U_{2}$. Let us define the cross current as:

$$
I_{\text {cross }}=\Delta U / r l=20 / 0.025 \cdot 1.5=530 \mathrm{~A} .
$$

Feeders current distribution is:

$$
I_{\mathrm{L} 1(2)}=I_{\mathrm{L} 1}+I_{\text {cross }}=634+530=1164 \mathrm{~A} \text {; }
$$

$$
I_{\mathrm{L} 2(2)}=566-530=36 \mathrm{~A} .
$$

When $\Delta U=21.2 \mathrm{~V}, I_{\mathrm{L} 2(2)}=0$, this case corresponds to single power supply.

The considered calculation methods of currents distribution in the traction network are suitable for the analysis of processes in one section in case of double power supply, but, practically, it is difficult to apply it for branched networks. The traction networks sections with double power supply are electrically connected throughout the entire transport route, where the substation may be a power supply, and a rolling stock in the brake mode may be an energy storage. This raises the problem of evaluating currents distribution from the power sources with different levels of voltage and the location of trains.

\section{DEFINITION OF CURRENTS DISTRIBUTION IN TRACTION NETWORKS WITH MULTIPLE SUPPLY CENTERS}

To determine the currents distribution in traction networks, one can use the equivalent electromotive force and current sources [9]. The essence of the method is comprised of the electromotive forces and the determination of equivalent conductivities, assessment of the currents in the branches by formulas:

$$
\begin{gathered}
U_{\mathrm{e}} \cdot q_{\mathrm{e}}=\Sigma U_{\mathrm{i}} \cdot q_{\mathrm{i}} ; \\
q_{\mathrm{e}}=\Sigma q_{\mathrm{i}} ; \\
U_{\mathrm{e}}=\Sigma U_{\mathrm{i}} \cdot q_{\mathrm{i}} / \Sigma q_{\mathrm{i}} ; \\
i_{\mathrm{Li}}=U_{\mathrm{i}} \cdot q_{\mathrm{i}} / \Sigma U_{\mathrm{i}} \cdot q_{\mathrm{i}} .
\end{gathered}
$$

In formulas (22-25), the following is indicated:

$U_{\mathrm{e}}, q_{\mathrm{e}}$ - equivalent electromotive force and conductivity;

$U_{\mathrm{i}}, q_{\mathrm{i}}-$ electromotive force and conductivity of the $i$-th branches of electrical circuit.

Let us consider the traction network of one track (Fig. 6), taking the following assumptions: the lengths of the sections are all identical and equal $l$ with parameter $r, \mathrm{Ohm} / \mathrm{km}$; traction current $I_{\mathrm{T} 1}$ is in the middle of sections S3, S4, i.e. $x=l / 2$. In the braking mode, train $-U_{\mathrm{r}}$ is located in the middle of section S2 with coordinate $x=l / 2$, the section length is modified, so feedlines resistance and internal resistance of substations are taken into account. The equivalent circuit for the evaluation of currents distribution on the route is shown in Fig. 10.

Conductivity of branches are defined by the formula:

$$
q_{\mathrm{i}}=1 / r \cdot l_{\mathrm{s}} \cdot n_{\mathrm{s}},
$$

where $n_{\mathrm{s}}=1,2,3 \ldots-$ numbers of sections in the branch;

$$
r=25 \cdot 10^{-3} \mathrm{Ohm} / \mathrm{km}-\text { traction network parameter; }
$$$$
U_{1}=U_{2}=U_{3}=U_{4}=U_{5}=U_{1} \cdot U_{r}=1.2 \cdot U \text {. }
$$ 


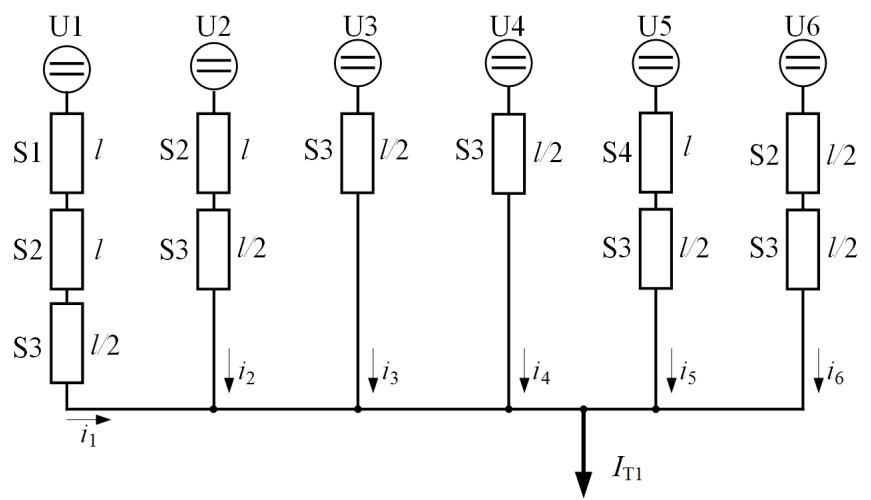

Fig. 10. Equivalent circuit for branches current assessment

The results of conductivities and branches currents calculations are listed in table 1. Table data show that the proportion of currents from connected to power supply sections does not exceed $60 \%$, and removed by one section is approximately by $20 \%$ (power supplies 2 and 5 ). Thus, $80 \%$ of the energy is adjacent to sections of 4 power supplies.

TABLE I. CONDUCTIVITY AND PROPORTION OF BRANCH CURRENT IN TRACTION CURRENT

\begin{tabular}{|c|c|c|}
\hline $\begin{array}{c}\text { № } \\
\text { branches }\end{array}$ & Conductivity, mho & $\begin{array}{c}\text { The proportion of branch } \\
\text { current in traction current, } \\
\%\end{array}$ \\
\hline 1 & 10.7 & 6.0 \\
\hline 2 & 17.8 & 9.9 \\
\hline 3 & 53.3 & 29.7 \\
\hline 4 & 53.3 & 29.7 \\
\hline 5 & 17.8 & 9.9 \\
\hline 6 & 26.6 & 17.8 \\
\hline
\end{tabular}

\section{CONCLUSION}

Currents distribution in traction networks is defined by power supply voltage and schemes, and by partitioning the contact network. The reasons for the different levels of power supply voltage are notequipotential supply centers, differences among external characteristics, use of electric braking energy. The notequipotential mode of the power supply is the natural state of the system. To determine the distribution of currents in the substation area, the method of nomograph is acceptable.

For the evaluation and analysis of currents distribution, the revised method of equivalent to electromotive force and conductivities, including a number of power sources is applicable. This method allows solving the task of choosing partition schemes of contact network and determining the electrical quantities with less error.

\section{Acknowledgment}

The reported study was funded by RFBR according to research project No. 16-08-00656.

\section{References}

[1] V. G. Sysenko VG, D.A. Bosvit, E.N. Kosarev, "Improvement of the methodology for calculating the distributed traction power-supply system with an amplifying point", Power electronics and power engineering, vol. 9, pp. 8-18, 2014.

[2] O.I. Sablin, "Improving the efficiency of energy recovery in the electric transport system with limited traction power supply", Technological audit and production reserves, vol. 5/1, pp. 21-26, 2014.

[3] V.V. Biryukov, A.V. Kulekina, "The calculation features of the electrical energy storage devices parameters in transport", IFOST 2016, pp. 41-43, June 2016 [The 11 International forum on strategic technology, p. 596, 2016].

[4] V.I. Sopov, N.I. Schurov, Y.A. Prokushev and A.A. Shtang, "Increasing the efficiency of the use of electrical energy in the sub-subsystem of electric transport", Improvement of technical means of electric transport, vol. 3 (29), pp. 115-123, Jule 2002 [Digest of scientific works of the NSTU, p. 189, 2002].

[5] E.N. Bykov, B.V.Panin, V.N.Pupynin, Traction networks of subways, Moskow: Transport, 1987.

[6] M.V. Tarnizhevsky, D.K. Tomlyakovich, Design of power supply devices for trams and trolleybuses, Moskow: Transport, 1986.

[7] K.G. Marquardt, Electrosupply of Electrified Railways, Moskow: Transport, 1982.

[8] M.A. Sleptsov, Fundamentals of Electric Transport, Moskow: Academy, 2006.

[9] L.A. Bessonov, Theoretical bases of electrical engineering, Moscow: Higher School, 1973.

[10] V.I.Sopov, V.V. Biryukov, Y.A. Prokushev, Y.A. Rylov, "Analysis of power supply systems for rolling stock with various schemes of traction networks", Abstract journal of VINITI RAS: Transport, Science, Engineering, Management, vol. 2 (2008), pp. 49-53, 2008. 